\title{
É PROIBIDO PROIBIR: AMBIGUIDADES E ENFRENTAMENTOS NA/PELA LINGUAGEM
}

\author{
Bate-Papo entre Lynn Mario Menezes de Souza e Walkyria Monte Mor
}

\author{
Lynn Mario Trindade MENEZES DE SOUZA \\ Universidade de São Paulo \\ lynnmario@gmail.com
}

Walkyria MONTE MOR

Universidade de São Paulo walkyriamontemor@gmail.com

Nunca pensei que fosse ver e viver novamente esse clima político que estamos vivenciando. Mortes por COVID-19, mortes de negros, discriminação crescente a negros, a LGBTQ+, a mulheres, manipulação nos cargos para benefiar uns e prejudicar outros, autoritarismo... Aliás, autoritarismo ou fascismo? Identifico como fascismo, já que vejo prevalecer o nacionalismo patriótico sobre os valores e direitos dos sujeitos (ou cidadãos), um governo autocrático... Bem, é autoritarismo também. Ao escreverem a biografia do Brasil, Schwarcz e Starling (2015) parecem nos dizer que aqui fascismo e autoritarismo se confundem. Eles parecem se confundir numa herança que, como descrevem as autoras, vem de um "sistema repressivo capaz de manter com sucesso a tampa do caldeirão e impedir a ebulição de qualquer atividade oposicionista" (p. 375).

Já vivemos isso. Primeiro, como crianças, estudantes e, então, já adultos. As crianças só falavam quando alguém lhes dirigia a palavra. Seguiam decisões feitas pelos pais ou responsáveis. Os estudantes formavam fila, cantavam o hino nacional, sentavam-se em fileiras nas salas, levantavam-se da carteira de modo reverente quando o professor (ou diretor, ou outra pessoa que tinha cargo importante na escola) chegava em sala, tinham que levantar a mão quando tinham uma pergunta a fazer, só podiam falar um de cada vez... tudo em nome de uma ordem, sem a qual não haveria progresso. Esses sistemas já faziam (e ainda fazem...) parte de um processo preparatório para a vida adulta. Era como se os 
papeis dos adultos já estivessem escritos para um roteiro a ser seguido.

E nós viemos a ser professores, heim, Lynn Mario. Mas achamos que os estudantes/jovens deveriam ter mais do que aquela alternativa de roteiro. O que pensávamos ou já percebíamos naqueles tempos que nos levou a esse modo de pensar? Com certeza, os vários movimentos contra a ditadura naquela época. Como Raul [Seixas], preferíamos ser a tal "metamorfose ambulante, do que ter aquela velha opinião formada sobre tudo".

Como era a formação docente daqueles tempos? Muita ênfase na "neutralidade". Como professora de língua inglesa no Brasil, no meu caso, aprendi que o que se ensinava em inglês era o idioma, resumido a vocabulário e gramática (muitas décadas se passaram!!! Rsrsrs). Também podíamos "ensinar" oralidade, com repetição de frases corretas e boa pronúncia, tudo de forma bem neutra e modelar. O currículo deveria ser cumprido, as sequências do conteúdo deveriam ser seguidas, os alunos avaliados de acordo com o planejamento de cada ano...

Não se sabe em qual momento a ficha cai, não é mesmo? Aquela forte herança de promover os modernistas e as vanguardas artísticas passava a imagem de um país que se atualizava; ao mesmo tempo, fazia valer o silêncio sobre "as intervenções arbitrárias, perseguições e prisões que atingiram as áreas da cultura e da educação" (SCHWARCZ; STARLING, 2015, p. 378). Quantas décadas se passaram dentro desse cenário? E se aquele roteiro não nos deixava felizes como adultos e professores, nossa agência de cidadãos insatisfeitos com o que víamos poderia se manifestar em nossas aulas, com um trabalho de conscientização, com inserções no planejamento, sem sair das regras estabelecidas. Tudo com muita cautela. Os professores eram seguidos pelas sombras do autoritarismo; seus nomes poderiam ser incluídos no DOPS ${ }^{1}$. E a história já havia ensinado sobre as ameaçadoras consequências.

\footnotetext{
${ }^{1}$ Departamento de Ordem Política e Social (DOPS). "Órgão histórico de repressão aos movimentos sociais e populares, o DOPS foi também centro de tortura durante a ditadura do Estado Novo, retomando essa prática no regime militar. Nos dois períodos ditatoriais, as vítimas preferenciais eram os militantes de partidos de esquerda. Com a centralização da repressão política pelos DOI-CODIs, a partir de 1969, passou a ter um papel secundário, mas não deixou de ser um porão da repressão, onde sevicias hediondas eram praticadas". Disponível em: <http://www.forumverdade.ufpr.br/caminhosdaresistencia/a-repressao/departamento-deordem-politica-e-social-dops/>. Acesso em: 18 set. 2020.
} 
Foi assim que, já como professores universitários, vimos nas ementas de nossos cursos uma oportunidade de interpretação/reinterpretação. Ou seja, percebemos que, mesmo tendo que seguir a descrição das disciplinas, em nome de uma homogeneidade curricular, poderíamos inserir outras ideias de modo a expandir perspectivas, proporcionando o rompimento de um jeito único de entender, de falar, de ver, de interpretar, de ser.

Sem mesmo saber como denominá-lo, colocávamos em prática aquilo que Hosford (1978) chamava de currículo silenciososo (the silent curriculum), definido pelo autor como "aquela parte do currículo que é criada somente quando ensinamos" (HOSFORD, 1978, p.212). Possivelmente, era o nosso jeito de promover resistência à noções de língua, linguagem, cultura, leitura, literatura, relação professor-aluno, relação universidadeescola-sociedade, que avaliávamos como engessadas. Não queríamos dizer que estavam erradas, mas que foram criadas, (provavelmente com objetivos didáticos?), ou mesmo inventadas como mais recentemente salientam Makoni e Pennycook (2006) acerca do conceito de língua. Observávamos que muitas daquelas concepções não mais correspondiam a uma sociedade em que heterogeneidade, diversidades, divergências, pluralidades pouco a pouco ganhavam visibilidade, depois de tanto tempo veladas ou sufocadas por modelos autoritários e arbitráriosnos modos de entender, de falar, de ver, de interpretar, de ser.

Assim, nas disciplinas pelas quais éramos responsáveis na universidade, reinterpretávamos desde as ementas até os sentidos já dados das coisas. Cá entre nós, Lynn Mario era um grande mestre na habilidade de reinterpretar ementas. Tinha sempre ótimas sugestões para a inserção de temas e questões que pudessem suscitar reflexões, questionamentos quanto às opressões, às repressões, aos raciocínios disciplinadores que eventualmente guiavam os aprendizes para visões, comportamentos, falas e escritas de comunicação adequadas às expectativas dominantes. Percebíamos haver uma discriminação velada - e nem sempre tão velada - no ambiente acadêmico. Quantos alunos sofriam o que hoje chamamos de bullying porque não falavam ou escreviam o idioma estrangeiro, ou mesmo a língua portuguesa, de acordo com a norma-padrão! Ou que não alcançavam a avaliação esperada! 
Ou que não tinham cultura suficiente ou sequer viajado para o exterior para querer cursar Letras.

Por conta dessas percepções, algumas teorizações (por exemplo, sobre relações de poder; descrição e prescrição nas línguas e culturas; o mito da língua inglesa; ler e interpretar, aliás, não chamávamos de meaning making naqueles tempos) e conteúdos foram introduzidos nas várias disciplinas. Algumas dessas não mais compõem o currículo de Letras. De qualquer forma, vale o registro das inserções ou intervenções feitas.

Em Leitura Intensiva ${ }^{2}$, por exemplo, voltada para o desenvolvimento da leitura em língua estrangeira, por meio de textos mais curtos, introduzimos textos com imagens, como tiras de jornal, charges e mesmo propagandas. A Leitura Extensiva ${ }^{3}$, por sua vez, recomendava a escolha de contos. No caso do curso de Letras-Inglês, não nos detíamos aos ingleses e americanos, como de praxe, incluíamos os contos latinoamericanos, africanos, russos, todos escritos em - ou traduzidos para a - língua inglesa. Era uma forma de os alunos terem acesso a outros universos culturais, por meio do inglês. Alguns (ou muitos) desses contos conduziam os leitores a questionamentos, reflexões nunca antes feitas, como registrado em vários dos depoimentos em nossas pesquisas. $\mathrm{O}$ impacto de "O Rinoceronte" (IONESCO, 1959), por exemplo, foi muito grande entre os jovens. Uma história sobre uma pessoa que pensa ouvir um rinoceronte... que ouve um rinoceronte... que, então, vê um rinoceronte... e depois passa a ver cada vez mais rinocerontes... que vê uma pessoa virar rinoceronte e, então, muitas outras também viram... e que, quase ao final, se questiona se também gostaria ou deveria se tornar um rinoceronte. Um texto muito instigante do teatro do absurdo que fez emergir discussões principalmente sobre consumismo, nazismo, manipulações.

As imagens também foram estudadas no desenvolvimento da escrita. A escrita argumentativa convencional e acadêmica expandia-se para a análiseda construção da

\footnotetext{
${ }^{2}$ Leitura intensiva - ler textos mais curtos à procura de detalhes. Esses modos de leitura muitas vezes acontecem simultaneamente. Disponível em: Leitura e Compreensão Textual, Cadernos do X CNLF, <www.filologia.org.br>. Acesso em: 07 set. 2020.

${ }^{3}$ Leitura extensiva - ler textos mais longos, geralmente por prazer.
} 
imagem (parada e em movimento, fotos e filmes) e dos sentidos.Era um trabalho que já identificava a multimodalidade, o letramento visual e crítico, quando esses termos e conceitos ainda não eram (ou eram pouco) conhecidos no meio acadêmico brasileiro.

Pois é, Walkyria, viemos a ser professores nesse cenário de autoritarismo/fascismo! Agradeço, seus comentários elogiosos a meu respeito, por ser "um grande mestre na habilidade de reinterpretar ementas", mas preciso explicar isso no contexto de fascismo/autoritarismo. Primeiro, reitero a sua citação de Schwarcz e Starling (2015) retratando o fascismo no Brasil como vinculado ao nacionalismo e traço da herança brasileira; você e eu cansamos de encontrar posturas fascistas, ou pelo menos autoritárias, entre colegas professores de língua inglesa, muitos dos quais seduzidos por um fascínio pelas culturas de língua inglesa; nesse caso, poderíamos dizer que aquele fascismo que observávamos tinha origem no fascínio pelo nacionalismo dos outros! Esse fenômeno está previsto no conceito de "regimes metadiscursivos" usado por Makoni e Pennycook (2006) que você já citou; usam o termo para descrever crenças predominantes, em dado momento da história, acerca de línguas e culturas e, acrescento, culturas e pedagogias.

De fato, a face mais visível do autoritarismo na nossa área de ensino de língua estrangeira, até pouco tempo atrás, era a fidelidade ao 'método'. Os professores aprendiam a ensinar com um determinado método, muitas vezes incorporado num determinado livro didático, e repetiam essa fórmula pelo resto de suas carreiras. Em vez de culpá-los pela repetição, precisamos entender o contexto fascista/autoritário reinante no país até o fim da ditadura na década de 80, contexto esse que, junto com o regime metadiscursivo reinante, normalizava a repetição de normas sem questioná-las.

Quanto à minha facilidade em reinterpretar normas, isso também surgiu num contexto específico. Como você sabe, cresci na Inglaterra racista das décadas de 60-70; como muitos em desvantagem em contextos semelhantes, fui confrontado por duas opções descritas da seguinte forma por Hannah Arendt (1963, p. 226): "sob as condições de terror, a maior parte das pessoas vai obedecer, mas algumas não vão". Aprendi a não obedecer, obedecendo; ou seja, descobrindo os espaços intersticiais em que podia-se 
resistir sem chamar a atenção. Esses espaços silenciosos sempre existem, mas muitos optam por não fazer isso. Nesse sentido, o tal de silent curriculum que Hosford menciona pode ter duas faces: a da concordância silenciosa com o status quo ou a da resistência silenciosa.

Aprendi cedo que diante de um status quo "fascista" que normaliza a desigualdade e o autoritarismo, quando se é minoria, a estratégia de resistência mais eficaz pode ser a de subversão silenciosa cotidiana sem confronto aberto. Essa estratégia não ganha a guerra de imediato, mas possibilita vencer muitas pequenas batalhas. Lembro-me bem de um exemplo disso. Já no Brasil, tive a oportunidade de ensinar inglês numa rede de escolas que se dizia bi-nacional mas na prática era mono-nacional; a rede, de grande prestígio, valorizava apenas a nação estrangeira a qual se aliava. Era a época da ditadura dupla (a militar e a do método/livro didático); eu ensinava inglês a grupos de adolescentes usando um livro didático importado que incorporava um método que garantia a aprendizagem de qualidade a todos os aprendizes de qualquer nação do planeta exatamente da mesma forma. Se não fosse uma imposição top-down, podia parecer uma proposta bem democrática...

Enfim, os adolescentes brasileiros que eram meus alunos tinham dificuldade para seguir o ritmo do livro didático imposto pela coordenação da rede (do tipo: "aula de segunda-feira: página $X$ a $Y$; aula de quarta-feira: página tal a tal"). Esse ritmo prescrito precisava ser registrado pelo professor em seu diário de aulas, e era conferido semanalmente pela coordenação; havia penalidades previstas para quem não obedecesse à ordem recomendada. Como minha lealdade enquanto educador era com os aprendizes, optei por seguir o ritmo de aprendizagem real dos meus alunos, ritmo esse bem mais lento que aquele previsto pela coordenação. Em muitos casos, achava desnecessário seguir as atividades de cada página e substituía-as por outras mais motivadoras. Restava, porém, o 'problema' de registrar o conteúdo das aulas no diário para posterior conferência pela coordenação.

Diante da injustiça potencial, optei, como muitos colegas, pela estratégia da "tradução 
entre práticas sociais": registrava diligentemente no diário da escola o conteúdo das aulas tal como previsto na ementa; mas, mantinha um diário particular com o conteúdo real aprendido por cada turma. Décadas mais tarde, Santos (2002, p. 274) diria que a tradução, longe de ser entre elementos verbais resultando num significado definido, é mais justa quando é entre práticas sociais; dessa forma o processo de tradução não é interrompido e não se reduz a diferença do outro à semelhança de si; pelo contrário, garante que ambas as partes perdurem no processo de tradução mútua: "o objetivo da tradução entre práticas [...] é criar as condições para uma justiça social global a partir da imaginação democrática". Assim, eu traduzia o progresso real de cada turma no progresso desejado pela coordenação. Apesar do processo tradutório nesse caso não ser mútuo, todos ganhavam... Batalha vencida, mas guerra nem tanto. Walkyria, como você disse em relação ao texto instigante de Ionesco, nesse episódio, eu deixava a coordenação da escola ouvir os rinocerontes que queria...

Nos tempos de hoje, com o aparente retorno do fascismo/autoritarismo (ainda não sei se é "retorno" ou "visibilização" de algo de nossa herança que permaneceu por algum tempo invisível), as velhas considerações de Hannah Arendt (1963) sobre a "banalidade do mal" ressoam em meus ouvidos. Inicialmente ela dirigiu essa expressão ao 'fascismo' nazista, mais particularmente a Eichmann, algoz nazista, e à sua declaração de que mandou milhões à morte nos campos de extermínio porque estava "apenas seguindo ordens". Mais tarde, Arendt explicou que, com essa sua expressão ela não se referia tanto ao mal do fascismo nacionalista alemã, e sim à ausência de pensamento que caracteriza muitos que aceitam as imposições de uma determinada norma social. Com relação a ação acrítica de muitos que se assujeitam a esse tipo de regime autoritário, ela assevera: "it was not stupidity but thoughtlessness" (1963, p. 284) ${ }^{4}$.

Muito recentemente essas suas palavras voltaram a ressoar em meus ouvidos. No mês de agosto, a convite da ALAB, intermediei uma palestra on-line de Walter Mignolo, pensador decolonial argentino radicado na Duke University nos Estados Unidos. Antes do evento, foi acordado entre as partes que o encontro seria em inglês, espanhol e português, já que

\footnotetext{
${ }^{4}$ não foi estupidez, mas falta de pensar direito.
} 
Mignolo não fala português e eu não falo espanhol, mas, ambos além de fluentes em inglês, entendemos essas duas outras línguas. Como é usual em encontros desses, a ALAB me forneceu, como mediador, uma apresentação formal sobre Mignolo escrita em inglês, a ser lida no início do encontro. Seguindo essa orientação, expliquei ao público no começo do evento que usaríamos as três línguas nas interações e iniciei a apresentação. Qual não foi minha surpresa ao ver no chat, correndo paralelo à interlocução inicial em inglês, comentários intolerantes da audiência reagindo contra o uso do inglês naquele momento inicial: "Falando com um dos teóricos da decolonialidade na língua do colonizador"; "tinha que ser em língua dos latinos"; "nada mais colonial do que falar em inglês... por que não usar o espanhol”; “cadê as línguas dos decolonizados?”.

Parece que esqueceram que tanto o inglês, quanto o português e o espanhol são línguas trazidas às Américas pelo colonizador. O que espanta nessa troca de mensagens é que por ser organizado pela $\mathrm{ALAB}$, provavelmente as pessoas na audiência eram professores de línguas e sabedores das teorias decoloniais que apontam a violência do processo colonial sofrida pelas populações indígenas das Américas. Como não ler essa ocorrência como sintoma do contexto atual do fascismo/autoritarismo nacionalista? Mignolo tratou de mencionar em sua fala que a opção decolonial é uma opção uma vez que não se trata de ser (obrigatoriamente) a favor ou contra, e sim de procurar outras formas de pensar e agir.

Como linguistas aplicados que somos, sabemos que apesar das três línguas em questão serem originariamente coloniais, seu(s) uso(s) não $\operatorname{precisa}(\mathrm{m})$ ser. Quando são usadas por falantes nativos monolíngues na comunicação com falantes de outras línguas, colocam esses últimos em flagrante desvantagem, atingindo assim o grau máximo de autoritarismo ("Fale na minha língua ou cale-se"). Porém, isso não ocorre num contexto como o daquele encontro, composto por falantes das três línguas, nenhum dos quais monolíngue, e todos, em teoria, sabedores da problemática decolonial e buscando por justiça social. Mas, nem tudo foi perdido. No mesmo chat paralelo surgiu uma luz da plateia: "português também é língua de colonizador. Eu falo cearense... rsrsrs".

Você vê, Walkyria, que o bullying linguístico que você mencionou, persiste! Lembremos 
que "fascistas" podem não ser apenas os outros. Como lembrou Schwarcz e Starling, o fascismo na sua vertente nacionalista pode ser um traço de nossa herança no Brasil e, portanto, tão estrutural quanto o racismo, despontando em momentos inesperados. Talvez seja o momento de, antes de embarcarmos na crítica necessária e urgente do fascismo (e do racismo) nos outros, refletirmos criticamente sobre esses aspectos em nós mesmos. Como diz Arendt (1974), a diferença entre o bem e o mal talvez não esteja nesses elementos em si; talvez esteja no processo de pensar e na opção de embarcar nesse processo ou não.

\section{REFERÊNCIAS}

ARENDT, H. Eichmann in Jerusalem: A Report on the Banality of Evil. London, Penguin, 1963.

ARENDT, H. The Life of the Mind: the groundbreaking investigation on how we think. San Diego, Harcourt Brace, 1974.

HOSFORD, P. L. The Silent Curriculum. Its Impact on Teaching the Basics. Educational Leadership, December 1978, p. 211-215.

IONESCO, E. Rhinoceros [1959]. Translated by Derek Prouse. New York: Grove Press, 1960.

MAKONI, S.; PENNYCOOK, A. Disinventing and Reconstituting Languages. Clevedon, Buffalo, Toronto: Multilingual Matters, 2006.

SCHWARCZ, L. M.; STARLING, H. M. Brasil: uma biografia. São Paulo: Companhia das Letras, 2015.

SANTOS, B. S. Para uma Sociologia das Ausências e uma Sociologia das Emergências, Revista Crítica de Ciências Sociais, n. 63, p. 237-280, 2002. 